\title{
Tumours of the third ventricle in children
}

\author{
BENNETT M. STEIN, RICHARD A. R. FRASER, \\ AND MICHAEL S. TENNER
}

From the Department of Neurological Surgery, Tufts-New England Medical Center, Boston, and Department of Radiology, Neurological Institute, New York, U.S.A.

SUMMARY Experience with 25 cases of tumour of the third ventricle in children is reviewed. The majority of the lesions were infiltrating astrocytomas of the anterior and mid-portions of the third $\frac{\bar{\sigma}}{\bar{N}}$ ventricle. These tumours were generally inoperable. However, other tumours within the third ventricle $\vec{\nabla}$ were benign, encapsulated, and resectable. Surgical exposure was carried out through one of three routes: posterior fossa, transcallosal, or subfrontal. The radiological criteria by which the operative approach is determined are discussed.

In children, if one excludes craniopharyngiomas, primary tumours of the third ventricle are uncommon. In a series of 100 childhood brain tumours (Walker and Hopple, 1949), 15 tumours were located in the third ventricle. Pecker, Ferrand, and Javalet (1966) reported nine childhood tumours of the third ventricle out of 35 cases. Almost all of the tumours in the children were astrocytomas. Cuneo and Rand (1952) observed that $15 \%$ of astrocytomas in children are located in the third ventricle, which was considered a favourite site for supratentorial tumours. Most surgeons have considered these tumours to be inoperable; accordingly a shunting procedure followed by radiotherapy has been the treatment of choice (Torkildsen, 1948; Ward and Spurling, 1948; Rand and Lemmen, 1953; Cummins, Taveras, and Schlesinger, 1960).

Twenty-five of our cases of third ventricular tumour in children seen in the past four years are reviewed. Although the astrocytoma predominated, a variety of other tumours occurred in this region and in some cases, because of encapsulation, were amenable to surgery. The route of surgical approach was determined by radiographic features of the tumour. We have categorized these lesions as follows: (1) posterior or pineal region; (2) centro-anterior or thalamic and foramen of Monro region; (3) inferior or hypothalamic-chiasmatic region.

Six illustrative cases of the 25 are presented.

\section{CASE 1}

R.Z., a 2 year old male, was admitted in 1967 with markedly increased intracranial pressure, right hemi- or paresis, and severe dehydration from persistent vomiting. A ventriculogram showed a large thira ventricular mass with a rounded contour (Fig. 1\$\$\& Because of the state of the patient a ventriculopleura shunt was carried out from both lateral ventricle This markedly improved his condition; the foch neurological findings gradually resolved and $\frac{8}{8}$ radiotherapy course of $5,000 \mathrm{r}$ was directed to the tumour. Four months later repeat ventriculograpk revealed no evidence of tumour (Fig. 1). The shunts were removed and he remains well four years after $?$ treatment.

\section{CASE 2}

S.M., a 4 month old male, was admitted in 1967 with a bulging anterior fontanelle, 'sunset' displacement of the eyes, and bilateral optic atrophy. Ventriculography showed a large mass filling the anterior third ventricle and obstructing the foramina of Monro. Air was noted in this cystic mass outlining its diaphenous wall (Fig. 2).

Using a transcortical approach, an ependymal cyst was removed from the third ventricle. Post- 8 operatively the child continued to manifest signs of $₹$ raised intracranial pressure and a pneumoencephalo- $ᄋ$ gram showed evidence of an incisural block. A ventriculoatrial shunt relieved this problem. The child has been followed for four years and, apart from mental retardation, is well. 


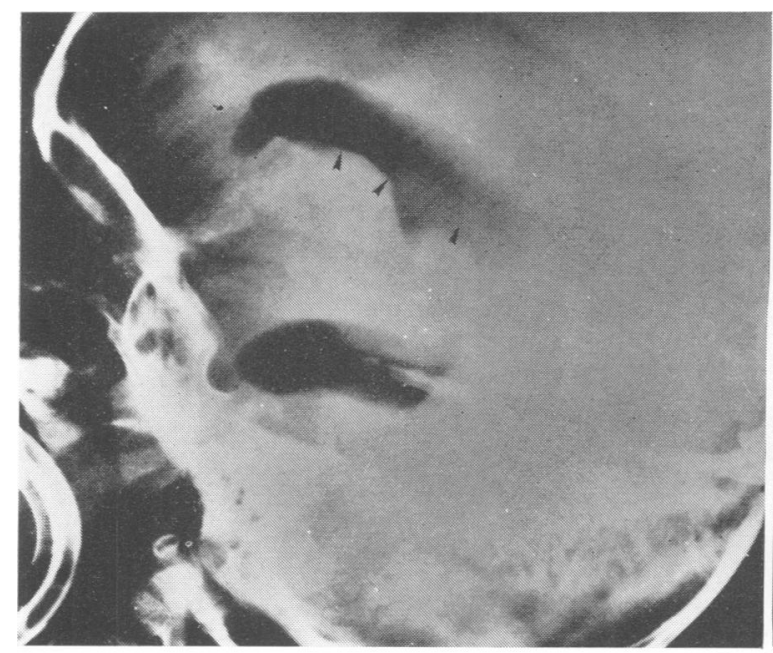

(a)

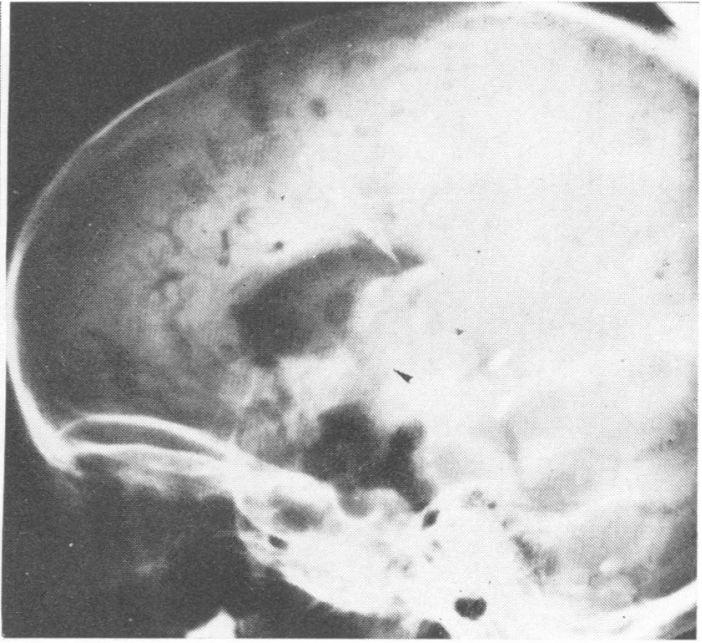

(b)

FIG. 1. Case 1. (a) Ventriculogram showing tumour filling the third ventricle and encroaching on the bodies and frontal horns of lateral ventricles (arrows). (b) Pneumoencephalogram post radiation showing regression of tumour and outline of air in the third ventricle (arrow).

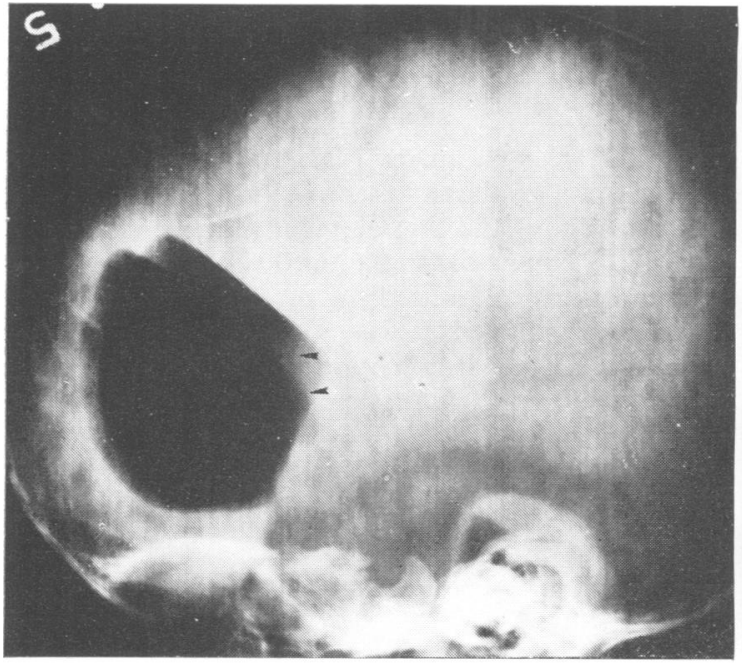

(a)

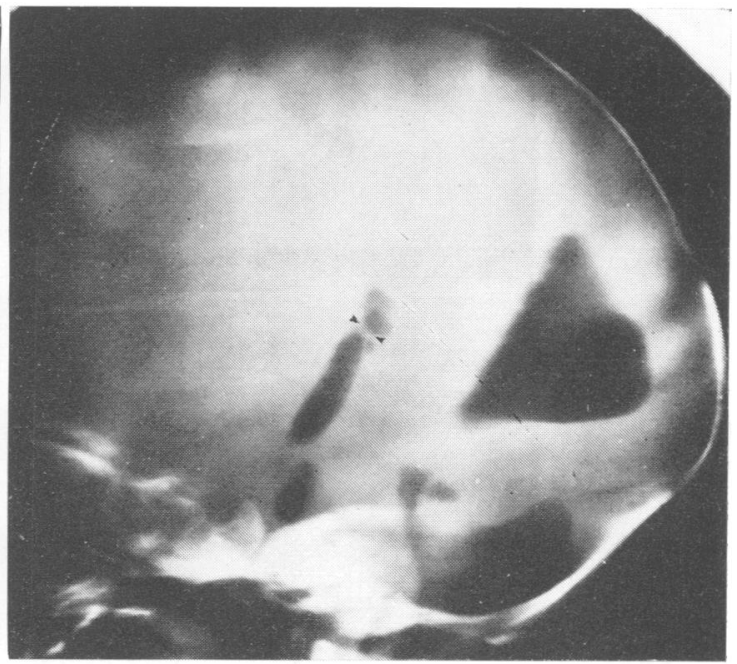

(b)

FIG. 2. Case 2. (a) Ventriculogram showing mass obstructing the foramina of Monro (arrows). (b) Pneumoencephalogram showing air which has entered third ventricular cyst separated from air within the third ventricle (dorsal) by the membranous wall of the cyst (arrows). 


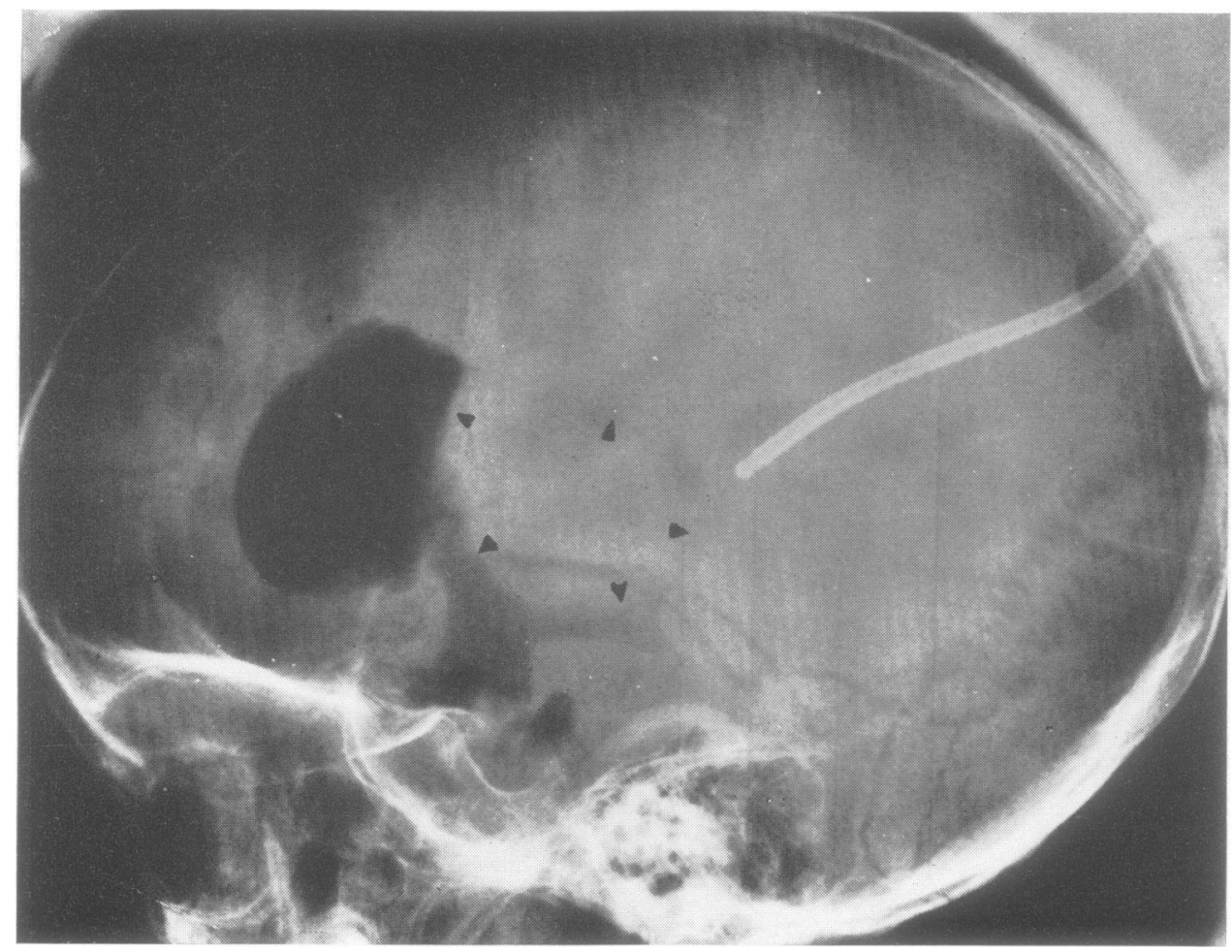

FIG. 3. Case 4. Ventriculogram showing tumour mass partially filling third ventricle. Extent of tumour indicated by arrows.

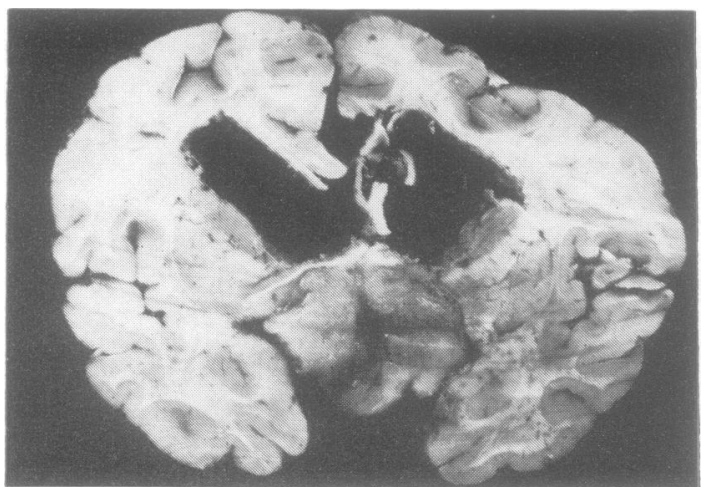

FIG. 4. Case 4. Coronal section of the brain demonstrating continued growth of tumour compared with extent observed at ventriculography (Fig. 3).
CASE 3

P.C., a $2 \frac{1}{2}$ year old male, was admitted in 1969 with an enlarging head and loss of vision, associated with optic atrophy and nystagmus. A ventriculogram revealed a large mass in the third ventricle. Through a frontal burr hole a needle was passed into the mass under $x$-ray control. It was not cystic and no tissue was obtained for examination. The child underwent a ventriculojugular shunt and received $5,000 \mathrm{r}$ of radiotherapy.

Apart from optic atrophy, the child has remained well, although we have no objective indication of the effect of radiation on this tumour of unidentified histology.

CASE 4

S.T., a $2 \frac{1}{2}$ year old female, was admitted in 1969 욱 with tremor, ataxia, and signs of raised intracranial $>$ pressure. A ventriculogram showed a large mass in the region of the anterior third ventricle which N appeared to arise from the right thalamus (Fig. 3). 


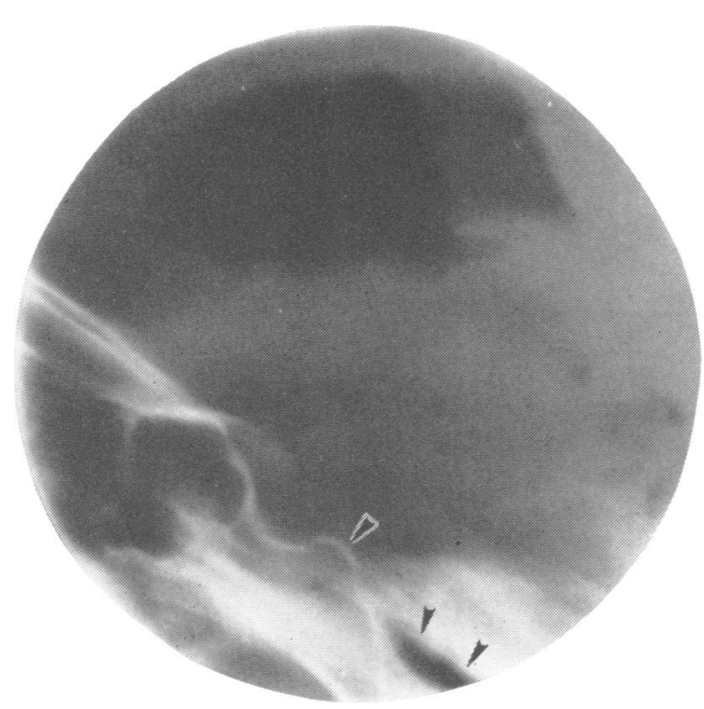

FIG. 5. Case 5. Combined ventriculogram-pneumoencephalogram showing large third ventricular tumour obstructing foramina of Monro and producing demineralization of the posterior clinoids and dorsum sellae and displacement of interpeduncular air (arrows).

The lesion was approached via a transcallosal exposure. A large infiltrating mass arising from the right side of the third ventricle was encountered. Biopsy disclosed an astrocytoma, grade II. A ventriculojugular shunt was installed. The child received a radiotherapy course of 5,000 r; however, the tumour continued to enlarge and she died 10 months later. The necropsy showed a large solid astrocytoma of the third ventricle and right thalamic regions (Fig. 4).

CASE 5

E.G., an 11 year old female, was admitted in 1968 with findings of raised intracranial pressure, without localizing features. Radiographs of the skull showed a deformity of the upper portion of the clivus and localized erosion of the dorsum sellae (Fig. 5). A brachial arteriogram showed lateral displacement of the posterior communicating artery and hydrocephalus, indicating an interpeduncular mass. A ventriculogram showed a large mass arising from the inferior portion of the third ventricle and extending into the interpeduncular space (Fig. 5). The lesion was explored via a subtemporal exposure on the right side (Fig. 6). An infiltrating exophytic astrocytoma of the hypothalamus was confirmed by biopsy and the patient received 5,000 $\mathrm{r}$ radiation postoperatively. She has remained well three years later.

\section{CASE 6}

K.L., an 11 year old female, was admitted in 1968 with mild ataxia, loss of upward gaze and of convergence of the eyes, and signs of raised intracranial pressure. A ventriculogram showed a large smooth mass in the posterior aspect of the third ventricle and pineal region (Fig. 7).

By a posterior fossa supracerebellar approach the region was exposed with the successful removal of an epidermoid tumour. The patient has remained neurologically normal.

\section{DISCUSSION}

Little attention has been devoted to the subject of tumours of the third ventricle in paediatric neurosurgical texts. However, extensive discussion may be found pertaining to lesions adjacent to this area such as craniopharyngiomas, pineal tumours, and hypothalamic gliomas (Jackson and Thompson, 1959; Matson, 1969). For the purpose of this report we have included pineal and hypothalamic-chiasmatic tumours as well as tumours arising directly within the third ventricle. Craniopharyngiomas were excluded, since they are rarely situated wholly within the third ventricle (van den Bergh and Brucher, 1970).

Dandy (1933) reported 16 tumours within the third ventricle. Most of these were classified as of glial origin, although a few cysts were included. Bailey, Buchanan, and Bucy (1939), under the classification of optic chiasm gliomas, reported 10 tumours all of which were astrocytomas. The experience of others writing on this subject is similar (Smith and Fincher, 1942; French, 1948; Odom, Davies, and Woodhall, 1956; Ford, 1966; Pecker et al., 1966; Lakke, 1969). It is, therefore, apparent that most tumours intrinsic to the third ventricle are astrocytomas, usually of low grade and arising from the diencephalon, hypothalamus, or optic chiasm. A small proportion of tumours in this region are ependymal cysts or colloid cysts (Buchsbaum and Colton, 1967).

Tumours arising in the pineal region often fill a large part of the third ventricle and, since they may invade this structure, should not be con- 


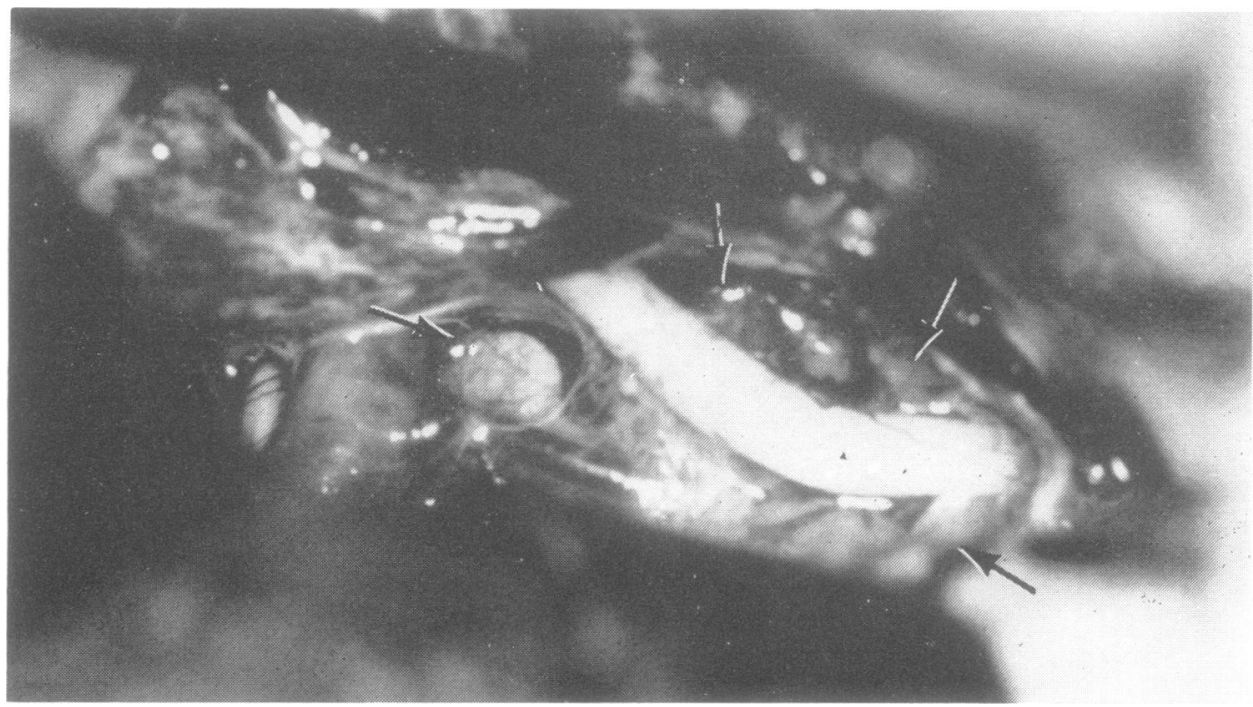

FIG. 6. Case 5. Subtemporal exposure of tumour (arrows) which is crossed by the oculomotor nerve (white structure) and bounded on the left by the carotid artery.

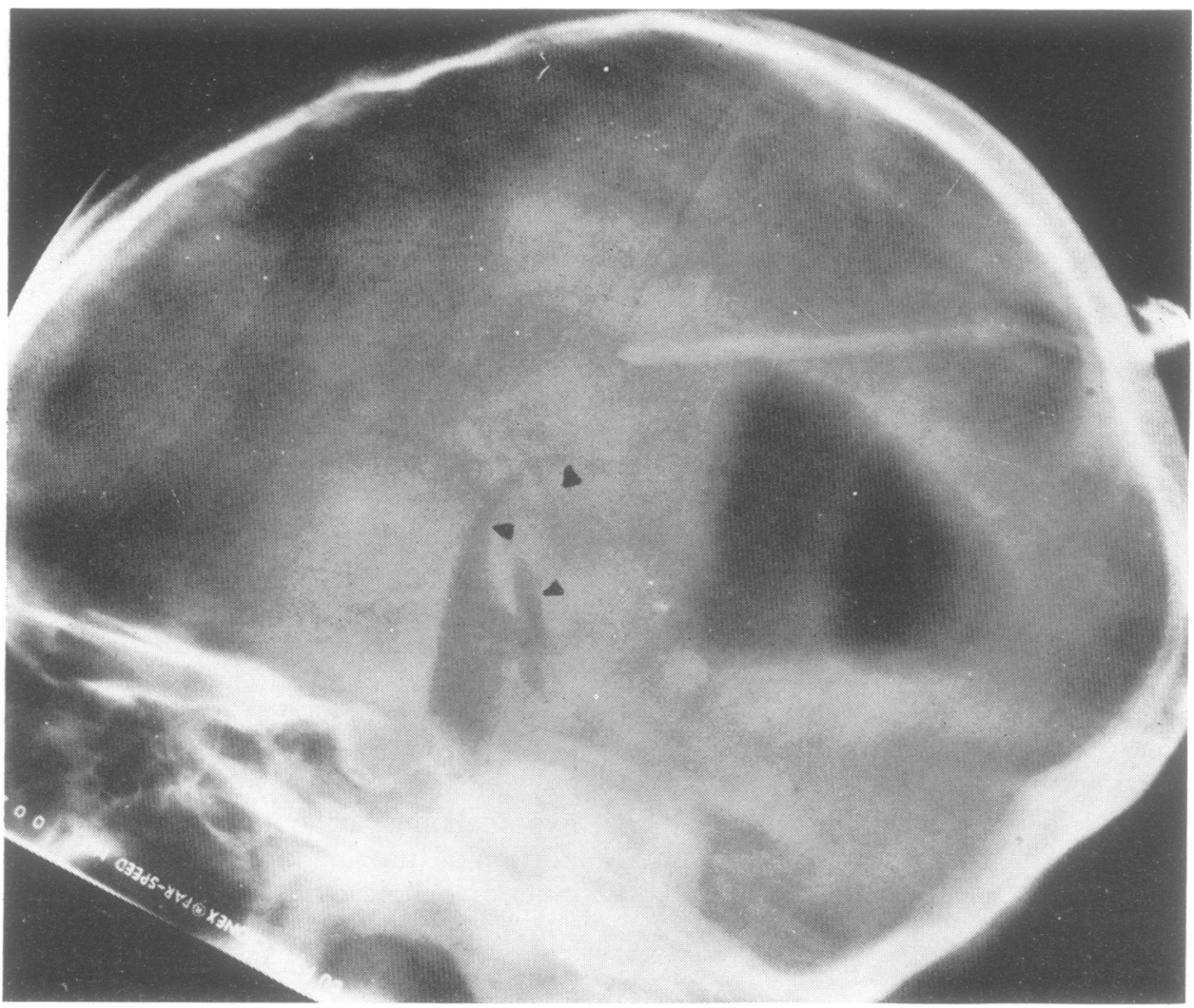

FIG. 7. Case 6. Ventriculogram showing distortion of posterior portion of a dilated third ventricle (arrows) by a pineal epidermoid. 
sidered purely as extra-axial masses (Rand and Lemmen, 1953; Stein, 1971).

The symptoms produced by these tumours vary somewhat according to their position (Weisenburg, 1911; Critchley, 1925; Dandy, 1933). More posterior tumours produce a midbrain or quadrigeminal plate syndrome while antero-inferior tumours are commonly associated with visual defects and signs of deranged hypothalamic function. It is not our intention to review the symptoms and signs, except to note that all of these tumours have in common the propensity to produce obstruction of cerebrospinal fluid flow early in their growth. This fact has relevance in their surgical management.

RADIOGRAPHIC FINDINGS In the plain radiographs of the skull there are few findings which are diagnostic of this group of tumours. Calcification, which occurs frequently in pineal tumours, is occasionally seen in cholesteatomas but is rare in the gliomas of this region (Camp, 1950). Oligodendrogliomas which have a high rate of calcification are rare in this age group and when present tend to involve the septum pellucidum and cerebral white matter. Because of the exophytic nature of some of these tumours, local erosive changes of the skull may be seen in the region of the clivus, dorsum sellae (Fig. 5), anterior and posterior clinoid processes, and tuberculum sellae. These changes are usually associated with gliomas of the chiasm or hypothalamus. Lesions which extend further anteriorly may erode the sphenoid wings or floor of the anterior fossa. Because of the proximity of third ventricular tumours to areas of the ventricular system readily susceptible to obstruction (foramina of Monro, posterior third ventricle and aqueduct), radiological changes of generalized increased intracranial pressure or hydro-

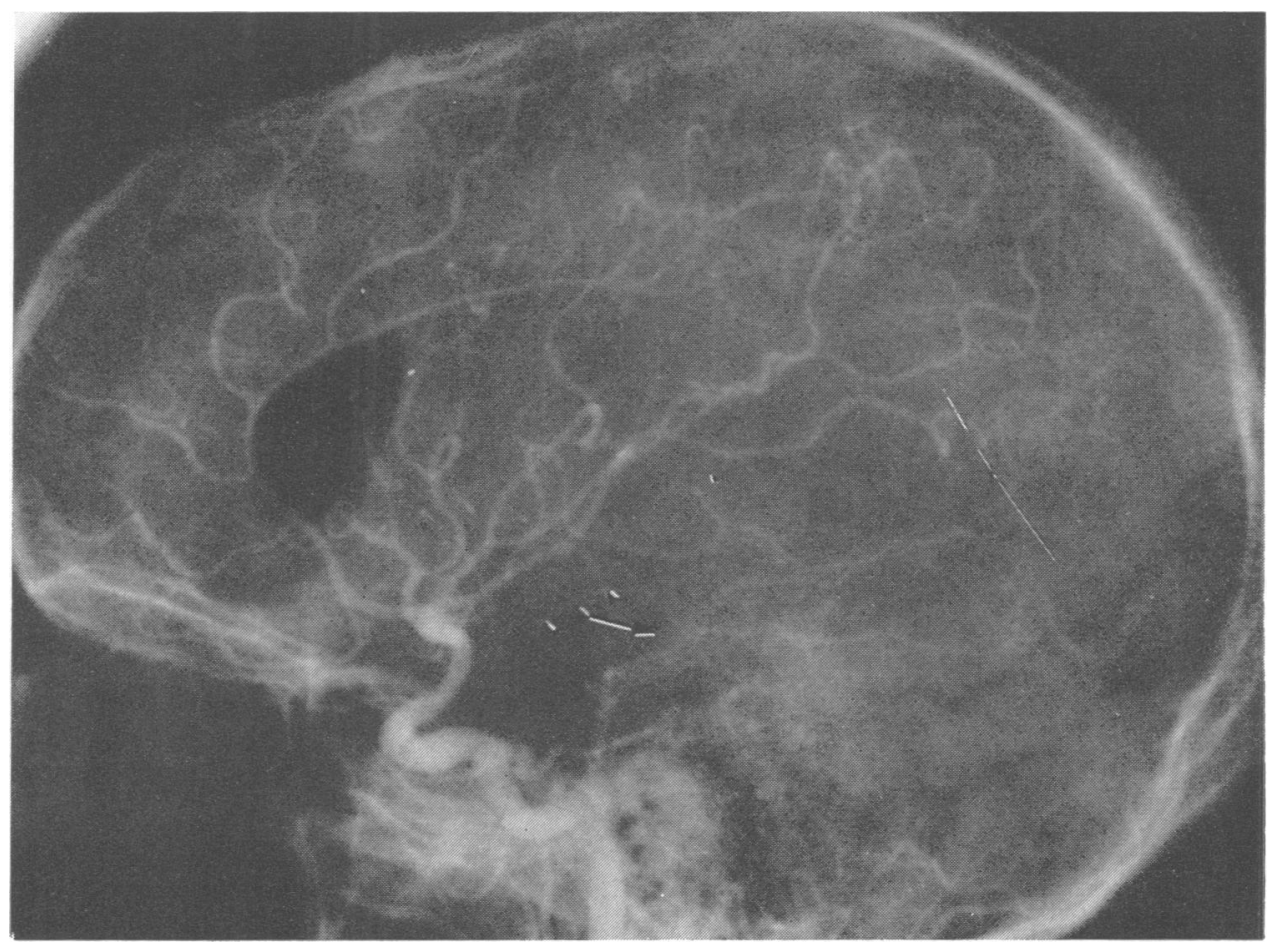

FIG. 8. Right brachial arteriogram lateral view. The carotid siphon is slightly open. The distal basilar artery is displaced backwards. There is separation and slight posterior displacement of the perforating thalamic vessels (arrow). The anterior choroidal artery is elevated and straightened (arrowheads). The pericallosal artery is elevated, indicating lateral ventricular enlargement. 
cephalus are common. These include: suture separation, cephalomegaly, ballooning of the sella turcica, and enlargement of the emissary venous channels.

Although pneumoencephalography or ventriculography has been the mainstay of diagnosis of these lesions, we have found that angiography is the best initial method of contrast study. The information obtained by angiography will often reflect the degree of hydrocephalus, will exclude vascular lesions such as aneurysms, malformation of the vein of Galen, and chiasmal arteriovenous malformation, and in the majority of patients will localize the lesion and give some clue as to the pathology.

Changes found in the antero-inferior group of lesions (Cassinari and Bernasconi, 1963) are lateral displacement of the distal part of the internal carotid artery, elevation of the hori- 음 zontal portion of the anterior cerebral arteries, $\bar{z}$ and reversal of the curves of the anterior chor- $\frac{}{2}$ oidal and posterior communicating arteries, on although the reverse curves may solely reflect an enlarged third ventricle. The thalamoperforate ${ }^{0}$ vessels originating from the posterior communicating artery and tip of the basilar artery will be found to be posteriorly displaced or fixed and $\vec{z}$

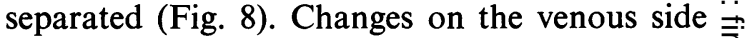
are primarily reflected by local upward dis- $\stackrel{0}{\rightarrow}$ placement of the septal vein and the anterior $\frac{}{c}$ portion of the internal cerebral vein (Potts and $\frac{\overline{\bar{N}}}{\bar{D}}$ Taveras, 1963). Larger tumours will displace $\frac{\pi}{\overparen{ }}$ laterally the uncal vein and basal vein of $\frac{Q}{0}$ Rosenthal.

The lesions of the mid-anterior third ventricu- $\vec{\circ}$ lar area are characterized by elevation and $\overrightarrow{\vec{\omega}}$ attenuation of the internal cerebral vein in

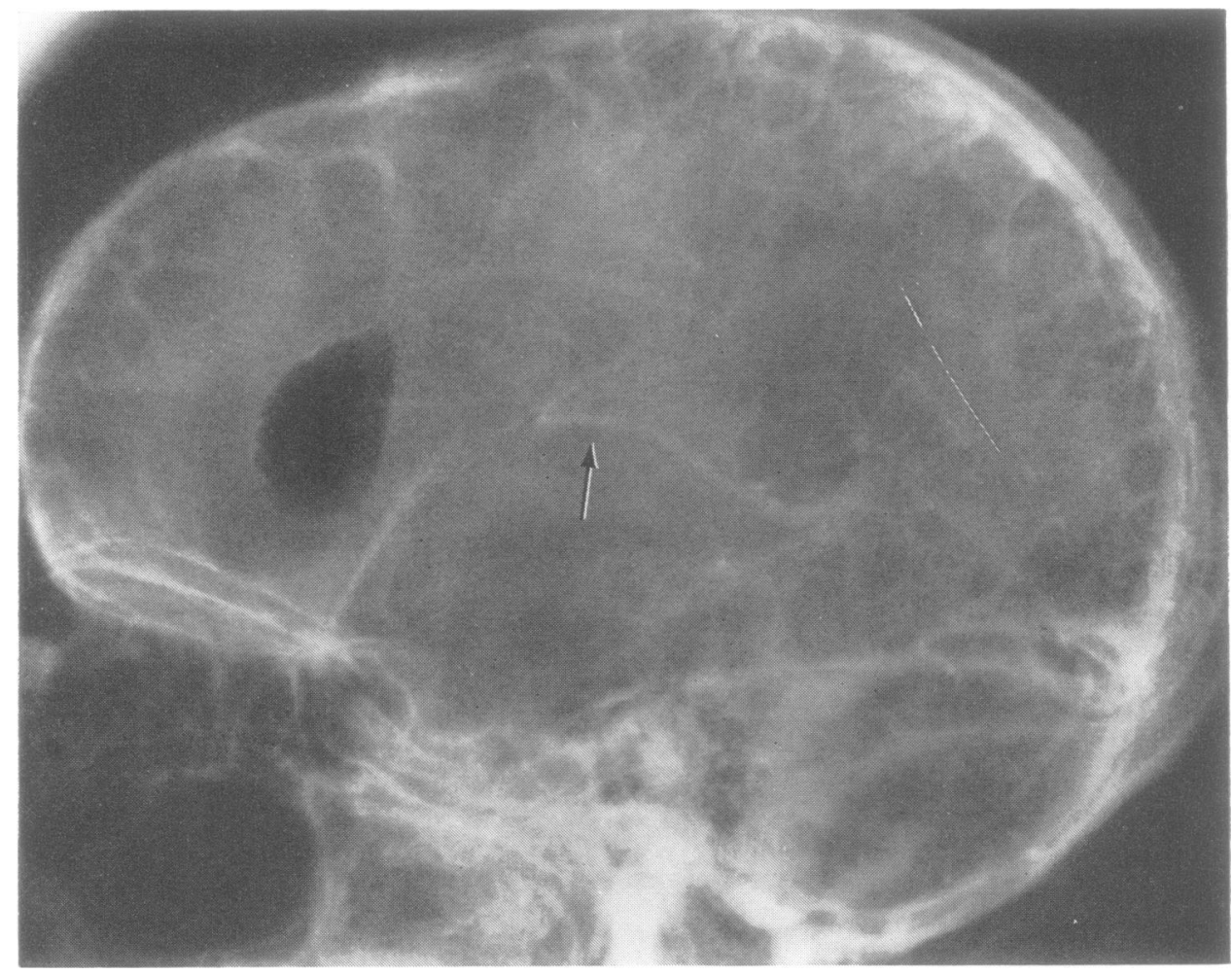

FIG. 9. Right brachial arteriogram, venous phase, lateral view. Elevation and attenuation of the internal cerebral vein from the region of the entrance of the thalamostriate vein posteriorly for approximately $1.5 \mathrm{~cm}$ (arrow). 
association with hydrocephalic changes (Fig. 9). Unless these lesions are very large, there may be little else to make the diagnosis. Large lesions will crowd together the thalamoperforate arteries, and if there is, sufficient lateral extension, displace the posterior cerebral arteries and basal veins of Rosenthal laterally and inferiorly.

Angiographic changes in the posterior group of tumours of the third ventricle are diagnostic in the majority of cases. When the lesions are relatively small the changes in the arterial phase may be confined to deformity of the medial branch of the posterior choroidal artery which is displaced upwards. As the lesion increases in size, other arterial structures are displaced as they pass around the posterior portion of the midbrain. This includes the posterior cerebral artery and, with infratentorial extension of the tumour, the superior cerebellar arteries. Charac- teristically, these tumours deform the posterior portion of the internal cerebral vein and the vein of Galen (Fig. 10). The majority cause local upward displacement of the vein, although occasionally the tumour may grow in a horseshoe fashion and cause a paradoxical downward displacement of the vein. As the lesion extends infratentorially, the precentral cerebellar vein is displaced backwards and the basal vein of Rosenthal displaced laterally.

Pneumoencephalography in the antero-inferior group of tumours will show deformity of the recesses of the anterior portion of the third ventricle. Air in the suprasellar and interpeduncular cisterns will further outline the extent of the lesion. Although the majority of these lesions are astrocytomas, the differential diagnosis includes cysts, dermoids, cholesteatomas, and other congenital tumours, as well as the rare non-

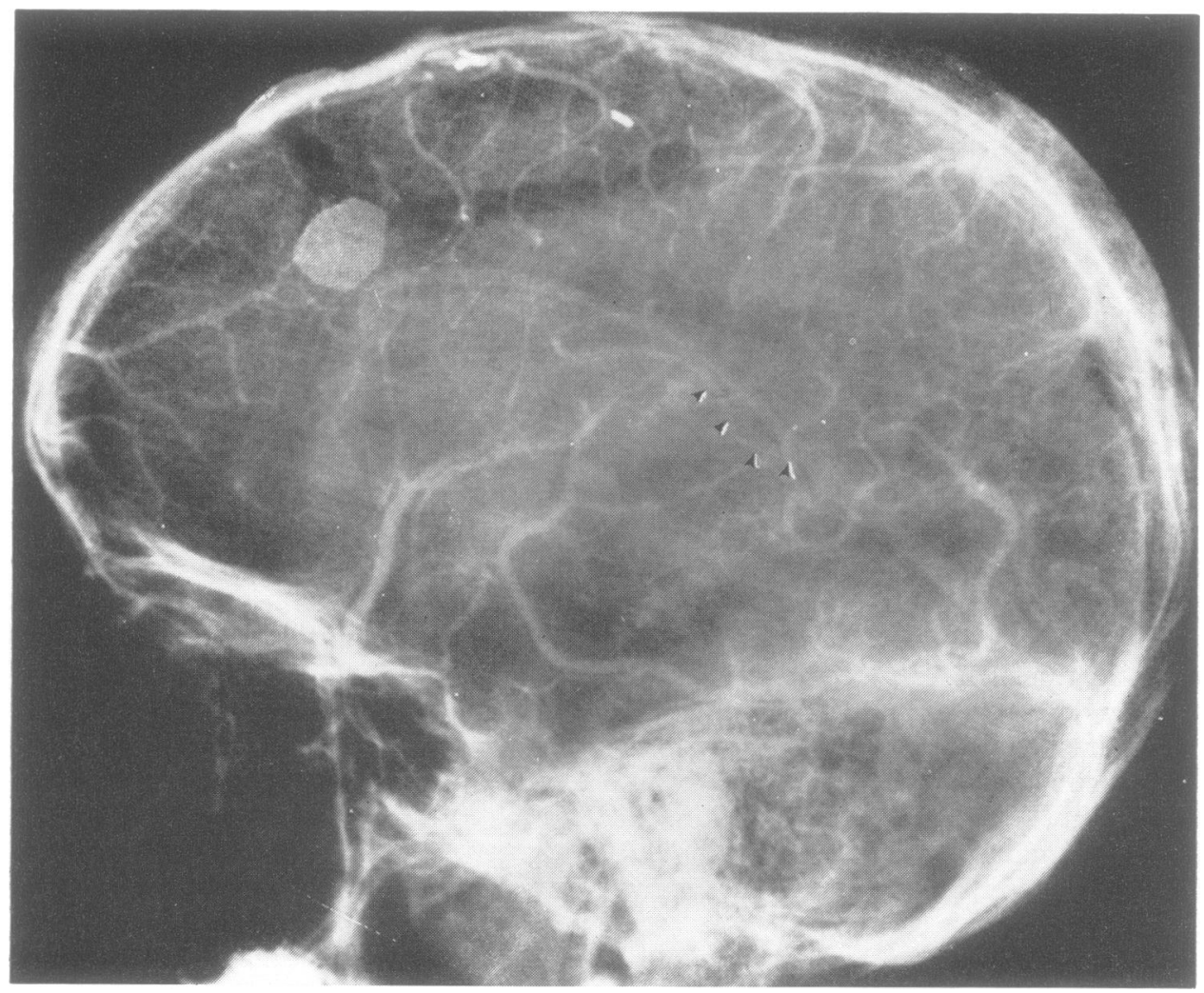

FIG. 10. Right brachial arteriogram, venous phase, lateral view. The posterior portion of the internal cerebral vein and the vein of Galen are elevated by a calcified pineal mass (arrows). 


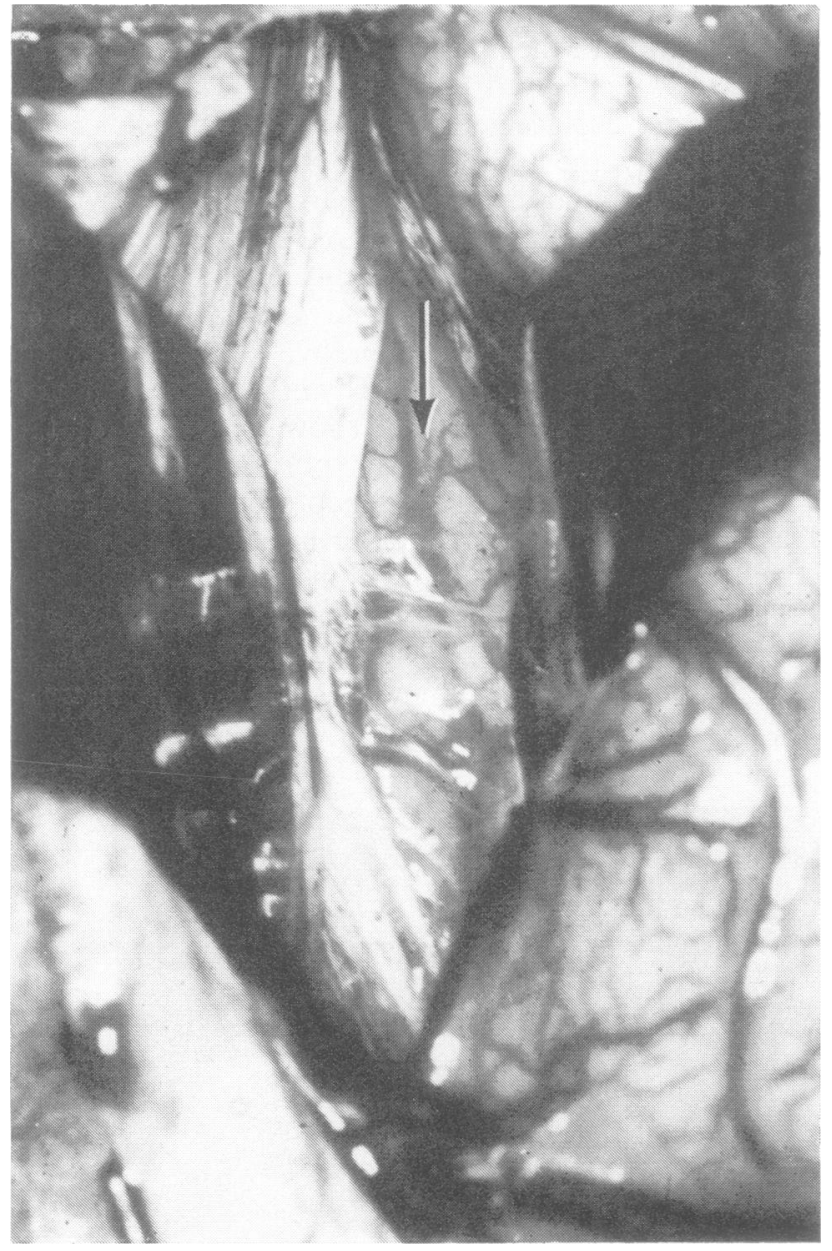

FIG. 11. Retraction of falx (left) and right cerebral hemisphere exposing the cingulate gyrus (arrow) before transcallosal approach to the third ventricle.

calcified craniopharyngioma. The difficulty of differentiating intra-axial and extra-axial lesions is compounded by the propensity of astrocytomas in this area to be exophytic, in part, and thus mimic extra-axial lesions.

Satisfactory demonstration of centro-anterior lesions is obtained through air studies. Occasionally both pneumoencephalography and ventriculography must be done in combination. A smooth rounded contour of the lesion should not convey the impression of a cyst, for many such lesions are solid (Figs 3 and 7).

In patients with posterior lesions, pneumoencephalography shows a characteristic deformity of the posterior portion of the third ventricle (Fig. 7). Air in the quadrigeminal cisterns outlines the postero-inferior extension of the lesion to best advantage. Again, in this $\varrho$ group of lesions there is frequently a need for $\overrightarrow{\overrightarrow{0}}$ both ventriculography and lumbar pneumo- $\exists$ encephalography to give complete delineation of the lesion and to provide differentiation from extra-axial lesions arising from the apex of the tentorium.

SURGERY On the basis of radiological and, to a lesser extent, the clinical findings, one of three possible surgical approaches was used in the $\mathrm{O}$ exploration of these tumours (Table).

For lesions of the posterior third ventricle or pineal region, an exposure through the posterior fossa was used (Stein, 1971). This operation, first 
TABLE

DETAILS OF CASES

\begin{tabular}{|c|c|c|c|c|}
\hline Case & Pathology & Operation & & urvival $(y r)$ \\
\hline 1 & Unconfirmed & Shunt, R.T.* & 4 & well \\
\hline 2 & Ependymal cyst & Transcortical removal of lesion & 4 & well \\
\hline 3 & Unconfirmed solid tumour & Shunt, R.T. & 2 & well \\
\hline 4 & Astrocytoma & Transcallosal biopsy, R.T. & 1 & died \\
\hline 5 & Astrocytoma & Subtemporal biopsy, R.T. & 3 & well \\
\hline 6 & Epidermoid-pineal & Posterior fossa removal of lesion & 3 & well \\
\hline 7 & Astrocytoma cystic & Subfrontal, subtotal, removal, R.T. & 1 & incapacitated \\
\hline 8 & Astrocytoma & Transcallosal biopsy, R.T. & 1 & incapacitated \\
\hline 9 & Malignant pineal & Transcortical biopsy, R.T. & died & \\
\hline 10 & Astrocytoma & Transcortical biopsy, R.T. & 2 & well \\
\hline 11 & Astrocytoma & Transcallosal biopsy, R.T. & 3 & well \\
\hline 12 & Astrocytoma & Transcallosal biopsy, R.T. & 1 & died \\
\hline 13 & Astrocytoma & Transcortical biopsy, R.T. & $6 / 12$ & died \\
\hline 14 & Astrocytoma & Transcortical subtotal removal, R.T. & 2 & alive \\
\hline 15 & Astrocytoma & Subfrontal subtotal removal, R.T. & 3 & incapacitated \\
\hline 16 & Astrocytoma & Subfrontal biopsy, R.T. & 2 & well \\
\hline 17 & Teratoma & Subfrontal, subtotal removal, R.T. & 3 & incapacitated \\
\hline 18 & Organized haematoma & Transcortical removal of lesion & $6 / 12$ & died \\
\hline 19 & Organized haematoma & Transcallosal removal of lesion & 2 & incapacitated \\
\hline 20 & Pineal arachnoid cysts & Posterior fossa, removal of lesion & 2 & well \\
\hline 21 & Pineal teratoma & Posterior fossa, removal of lesion & 4 & well \\
\hline 22 & Pineal teratoma & Posterior fossa, subtotal removal, R.T. & 3 & incapacitated \\
\hline 23 & Pineal teratoma & Posterior fossa, subtotal removal, R.T. & 1 & well \\
\hline 24 & Pineal atypical teratoma & Posterior fossa, biopsy, R.T. & 1 & well \\
\hline 25 & Pineal cystic astrocytoma & Posterior fossa, biopsy decompression, R.T. & 1 & died \\
\hline
\end{tabular}

* R.T.= radiotherapy.

reported by Krause (1926), is made between the superior surface of the cerebellum and the tentorium. Such an approach has been used for seven pineal lesions without morbidity or mortality.

In only two of these cases, an atypical teratoma and a low-grade astrocytoma, was the tumour invasive. The remaining five cases represented the following pathology: epidermoid, cystic arachnoiditis, and three teratomas, which were encapsulated. In four of these cases a significant portion of the tumour was removed and the patients improved. Six of the seven cases remain alive and well six months to four years after surgery.

For lesions located about the anterior or foramen of Monro region of the third ventricle either a transcallosal or transfrontal cortex approach has been used. The former was used in five cases and the latter in six cases. The transcallosal approach is preferred because the operator has access to both lateral ventricles as well as the third ventricle through the foramina of Monro.

This operation is done with the patient in the semi-upright position. By decompressing the ventricular system the corpus callosum may be exposed by retracting the non-dominant hemisphere from the falx cerebri (Fig. 11); the exposure being centred at the coronal suture (Dandy, 1933). Division of the corpus callosum is usually made between the anterior cerebral arteries (Fig. 12). Upon entering the ventricular system the only difficulty that may be encountered is distinguishing one lateral ventricle from the other. However, with attention to the details of the ependymal venous pattern and the course and position of the choroid plexus this differentiation may be made easily. In cases operated on by this route, little more than a biopsy could be accomplished, since all of the lesions were non-cystic of infiltrating low-grade astrocytoma type. No ependymomas were encountered.

By the standard transfrontal exposure an incision is made anterior to the coronal suture through the middle frontal gyrus and the anterior position of the frontal horn is entered (Dandy, 1933). Unlike the transcallosal approach, exposure of the opposite ventricle, ventral portions of the third ventricle, and the body of the ipsilateral lateral ventricle is difficult. The six lesions approached by this route repre- 


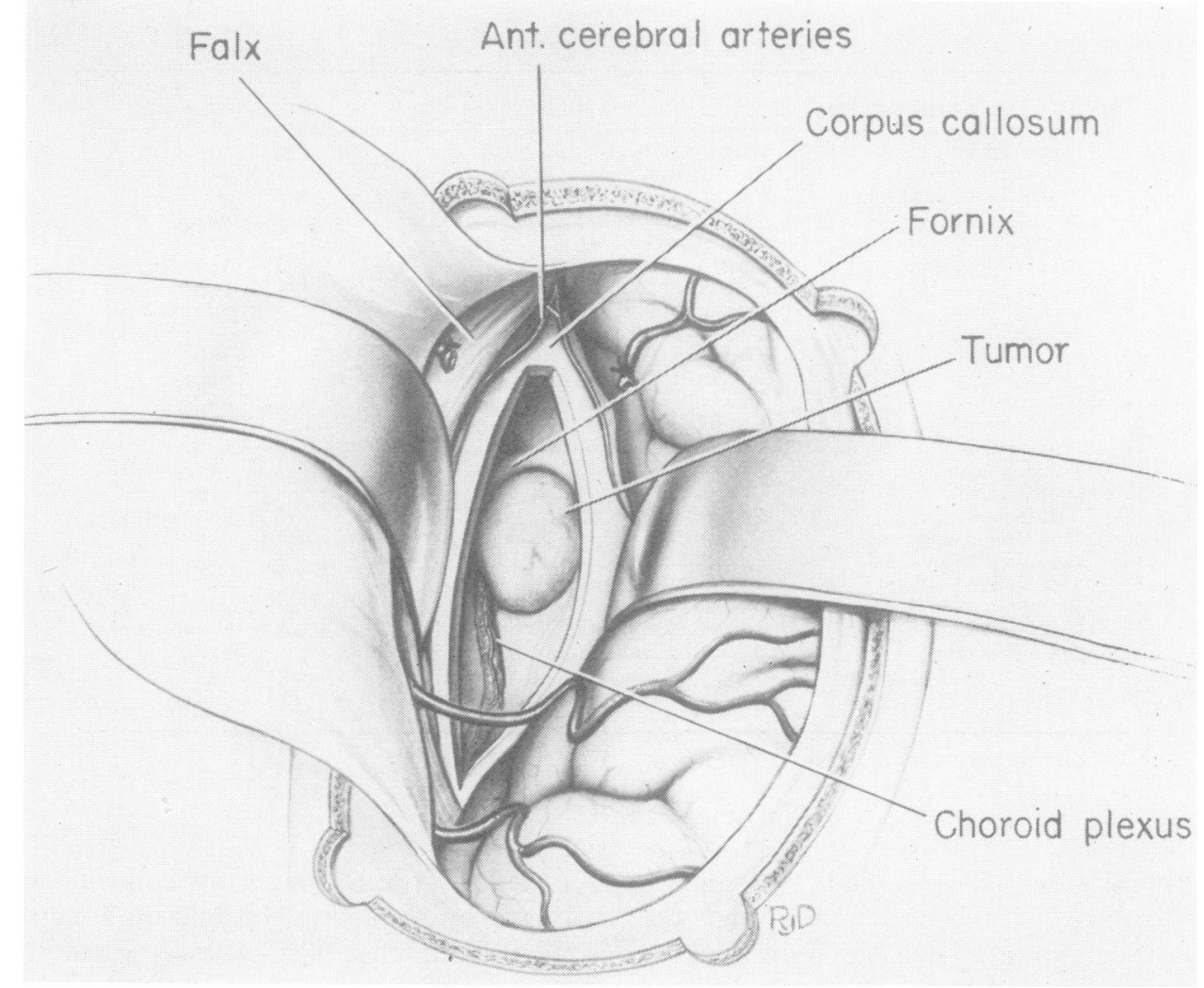

FIG. 12. Drawing of transcallosal exposure of a third ventricular tumour. The right cerebral hemisphere is being retracted from the falx after sectioning an anterior cortical vein.

sented a variety of pathology. In three cases infiltrating astrocytomas were encountered and little more than biopsy was accomplished. In one case diffuse ventricular seeding from a malignant tumour, probably of pineal origin, was encountered. This was similar to the cases described by Ford (1966). In one case an ependymal cyst attached to the infundibular region of the third ventricle was removed and in another a large haematoma, a complication of diffuse arteritis, was removed from the foramen of Monro region.

Of these 11 cases five are dead and the remainder alive two to four years after surgery.

A final series of five cases with tumours which arose primarily in the inferior portion or hypothalamic-chiasmatic region of the third ventricle were approached by the standard subfrontal or, in one instance, a subtemporal route. The latter procedure was used because of radiographic evidence of an exophytic hypothalamic tumour which displaced the posterior communicating artery and grooved the dorsum sellae. In accordance with previous experience, most of these tumours were low-grade astrocytomas which were infiltrating and non-resectable. One of these tumours was an exophytic teratoma of the third ventricle and another, an astrocytoma, contained a huge cyst which extended subfrontally. All of the children are alive one to four years after operation and radiotherapy, but three are impaired.

In one instance (case 1) because of a critical state on admission the child underwent a shunting procedure followed by radiotherapy, without histological confirmation of the type of tumour. A follow-up pneumoencephalogram after com- 
pletion of radiotherapy showed complete disappearance of the tumour. The conclusion was that this was a highly radiosensitive tumour, perhaps an ependymoma.

In one child (case 3 ) the radiographic appearance of a smooth-walled mass in the central portion of the third ventricle was so suggestive of a cyst that a needle was placed in the central part of the tumour via a frontal burr hole. Obtaining no fluid, the assumption was made that this was a solid tumour, most likely an astrocytoma. A shunting procedure was done followed by radiotherapy. Both of these children are well two and three years respectively after surgery. Neither has a confirmed histological diagnosis.

This experience has led to the conclusion that a high proportion of anterior and inferiorly placed masses within the third ventricle are lowgrade infiltrating astrocytomas. Such was the case in 11 of 16 confirmed tumours. The remaining five were as follows: two organized haematomas presenting as masses, one malignant presumed pineal tumour, one cyst, and one teratoma.

All of these tumour cases received postoperative radiotherapy. Although follow-up encephalograms were done in only a few instances, when performed there was evidence of little change in the size of the astrocytomas. The clinical course of the astrocytoma cases also would suggest that radiotherapy did not materially effect the tumour.

In the case of the posterior third ventricular or pineal tumours such heterogeneous pathology is encountered that these tumours should not be regarded with the same pessimism as are other tumours within the third ventricle. This is probably due in the strictest sense to their extraventricular origin. Therefore in the case of tumours of the posterior third ventricle, the surgeon may reasonably expect to accomplish more than just a biopsy (Stein, 1971), while in other third ventricular tumours biopsy alone is the usual procedure and little can be done to alter the otherwise dismal outlook of the infiltrating tumours; even by the installation of shunts and use of radiotherapy.

\section{CONCLUSIONS}

Our experience with tumours of the third ventricle has been reviewed. Three operative exposures including posterior fossa, transcallosal, and subfrontal are used to expose these lesions.

The vast majority of anterior and inferiorly situated third ventricular tumours represent infiltrating slow growing astrocytomas which are not amenable to surgical removal and which respond poorly to radiotherapy.

Tumours of the posterior third ventricle are occasionally encapsulated and can be removed surgically.

Because of the possibility of cystic or resectable lesions in the face of an otherwise limited outlook we recommend surgical exposure and histological confirmation of all tumours within the third ventricle.

\section{REFERENCES}

Bailey, P., Buchanan, D. N., and Bucy, P. C. (1939). Intracranial Tumors of Infancy and Childhood. University Press: Chicago.

Bergh, R. Van den, and Brucher, J. M. (1970). L'abord transventriculaire dans les crânio-pharyngiomes du troisième ventricule. Aspects neuro-chirurgicaux et neuro-pathologiques. Neurochirurgie, 16, 51-65.

Buchsbaum, H. W., and Colton, R. P. (1967). Anterior third ventricular cysts in infancy. Case report. Journal of Neurosurgery, 26, 264-266.

Camp, J. D. (1950). Significance of intracranial calcification in the roentgenologic diagnosis of intracranial neoplasms. Radiology, 55, 659-667.

Cassinari, V., and Bernasconi, V. (1963). Tumori della parte anteriore del terzo ventricolo. Acta Neurochirurgica, 11, 236-271.

Critchley, M. (1925). Brain tumours in children; their general symptomatology. British Journal of Children's Diseases, 22, 251-264.

Cummins, F. M., Taveras, J. M., and Schlesinger, E. B. (1960). Treatment of gliomas of the third ventricle and pinealomas; with special reference to the value of radiotherapy. Neurology, 10, 1031-1036, 1960.

Cuneo, H. M., and Rand, C. W. (1952). Brain Tumors of Childhood. Springfield: C. C. Thomas.

Dandy, W. E. (1933). Benign Tumours in the Third Ventricle of the Brain: Diagnosis and Treatment. Thomas: Springfield.

Ford, F. R. (1966). Diseases of the Nervous System in Infancy, Childhood, and Adolescence. Thomas: Springfield.

French, L. A. (1948). Brain tumors in children. Minnesota Medicine, 31, 867-874.

Jackson, I. J., and Thompson, R. K. (1959). Pediatric Neurosurgery. Thomas: Springfield.

Krause, F. (1926). Operative Freilegung der Vierhügel, nebst Beobachtungen über Hirndruck und Dekompression. Zentralblatt für Chirurgie, 53, 2812-2819.

Lakke, J. P. W. F. (1969). Report on 16 intraventricular brain tumors: a clinical study. European Neurology, 2, 158174.

Matson, D. D. (1969). Neurosurgery of Infancy and Childhood. 2nd edition. Thomas: Springfield. 
Odom, G. L., Davis, C. H., Jr., and Woodhall, B. (1956). Brain tumors in children; clinical analysis of 164 cases. Pediatrics, 18, 856-869.

Pecker, J., Ferrand, B., and Javalet, A. (1966). Tumeurs du troisième ventricule, Neurochirurgie, 12, 1-136.

Potts, D. G., and Taveras, J. M. (1963). Differential diagnosis of space-occupying lesions in the region of the thalamus by cerebral angiography. Acta Radiologica, 1, 373-384.

Rand, R. W., and Lemmen, L. J. (1953). Tumors of the posterior portion of the third ventricle. Journal of Neurosurgery, 10, 1-18.

Smith, W. A., and Fincher, E. F. (1942). Intracranial tumors in children: preliminary study of 100 cases. Southern Medical Journal, 35, 547-554.

Stein, B. M. (1971). The infratentorial supracerebellar approach to pineal lesions. Journal of Neurosurgery, 35, 197-202.

Torkildsen, A. (1948). Should extirpation be attempted in case of neoplasm in or near the third ventricle of the brain? Experiences with a palliative method. Journal of Neurosurgery, 5, 249-275.

Walker, A. E., and Hopple, T. L. (1949). Brain tumors in children. 1. General considerations. Journal of Pediatrics, 35, 671-687.

Ward, A. A., Jr., and Spurling, R. G. (1948). The conservative treatment of third ventricle tumors. Journal of Neurosurgery, 5, 124-130.

Weisenburg, T. H. (1911). Tumours of the third ventricle, with the establishment of a symptom-complex. Brain, 33, 236-260. 